\title{
WHEN A PLACE BECOMES A COMMUNITY: Music, radio and the reach of social aesthetics
}

\author{
Transforming Cultures eJournal, \\ Vol. 4 No 1, April 2009 \\ http://epress.lib.uts.edu.au/journals/TfC
}

\section{Charles Fairchild ${ }^{1}$}

\begin{abstract}
What questions do we face when the familiar, informal or semi-formal modes of musical place-making are constituted instead by formal institutions whose explicit recognition by the state and the market are necessary for their existence and survival? A community radio station is one such institution. Their participants' primary goal is to enact different ways of producing culture, doing so by constructing a series of social relationships crafted through acts of communication and organisation that define the institution itself. The scholarly consensus has it that the ways of producing culture through community media enact a distinctly civil discourse that challenges traditional notions of cultural belonging, citizenship and the public sphere. The bare, simple fact that the vast majority of programming materials on most community radio stations in Australia is music begs a series of questions about the role of the social aesthetics of music in the construction and maintenance of institutions of civil society. I argue that we can draw out of these institutions the core values of a civil or democratic aesthetics specifically through understanding the type and character of the kinds of relationships that constitute them. Moreover, these relationships present an enticing contrast to the commercial relationships which dominate most of consumer culture.
\end{abstract}

\section{Introduction}

Over the past three or four years I have conducted intermittent fieldwork at community radio stations in Canberra and Sydney. I have come across a wide range of musical attitudes, styles and practices. Many of these practices could probably be interpreted and safely contained by a traditional reliance on a familiar constellation of ideas such as authenticity, false consciousness, the creation of affective alliances, the contestation of the hegemony exerted by those with access to social capital or the ability to dominate the continuously contested terrain of symbolic power (see Storey, 1998). However, community radio stations are not simply informally constituted groupings of individuals

\footnotetext{
${ }^{1}$ Charles Fairchild teaches at the University of Sydney.
} 
linked by discrete sets of textual or stylistic expressions. We are also talking about people working within institutions specifically designed to present us with communicative and expressive forms of musical place-making that are constituted by that organisation's modes of practice, the form of which is quite literally, popular. Further, the formal contours of these institutions must be recognised by the state and the market to exist. Therefore, we need to understand these institutions as participating in a broadly construed public sphere as part of civil society.

As I have argued elsewhere, the production of culture through community radio stations requires participants to enact a distinctly civil discourse, doing so by constructing a series of social relationships crafted through the very acts of communication and organisation that define the institution itself (Fairchild, 2006). Given that the vast majority of programming on most community radio stations in Australia is music, this brings to the fore a series of issues about the role of the social aesthetics of music in the construction and maintenance of institutions of civil society. By understanding the musical practices of community radio, we can draw out of these institutions the core values of a civil or democratic aesthetics specifically through understanding the type and character of the kinds of communicative relationships that constitute them.

\section{The musical practices of community radio}

In order to look at the character and content of the types of communicative relationships I'm talking about, I'd like to start with a story from which I want to draw out a few values that I will later claim are demonstrative of a civil or possibly even a democratic aesthetics. These values were made manifest to me through the specificity of the relationships the people I've interviewed and observed were trying to create by presenting music on radio. These communicative relationships are central to their experience of community, both imagined and material. Just as importantly, the specificity of their experiences grows directly from the civil and occasionally the democratic character of these largely aesthetic relationships. I'd like to focus primarily on the character and quality of these relationships and their connection to broader ideas of the production of place in the form of an idealised and an actual community. 
In November 2007, I went to a community radio station in Canberra to interview a music presenter I had spoken to several times before. I had arranged to meet him towards the end of his two hour show so I could record the first part of it and watch the rest as he presented it. Listening to a show and watching it get done are distinctly different experiences, a fact made abundantly clear in the time it took me to make the short trip to the studio. When I left the presenter had been playing a Fairport Convention tune. When I arrived, he was playing Chaka Khan. I'm still not sure how he got from one to the other nor how he made it work, but I know that he did, at least on his own terms. However, I also know that, at least in his own estimation, it almost didn't.

I could tell something was wrong when I arrived at the studio. While this particular presenter had usually been taciturn to the point of seeming disinterest, when I arrived there was a minor spout of chaos churning away inside the booth, inaudible from behind the studio glass. After some minutes standing outside looking into the studio, I was waved inside. The presenter, who I knew fairly well, didn't even look up. He simply kept up his semi-frantic movements while standing behind the mixing desk. He said distractedly, 'I think I've boxed myself into a corner here.' Had I not met him before, I probably would not have known what he meant by this somewhat cryptic, unelaborated comment. He wasn't referring to some mundane complication with the technology or the fact that he was in hurry to get somewhere else, but couldn't get out of the studio. He was instead, referring to the inchoate, improvisational aesthetic acts he used to organise his program. He was telling me that the aesthetic logic which he painstakingly crafted and applied to his show wasn't quite turning out the way he planned. He did eventually finish it off to his own satisfaction. After Chaka Khan he played an unfamiliar Ben E. King tune, a Chiffon's B-Side called 'Teach Me How,' concluding his show with 'Love' by John Coltrane. As he took the headphones off after setting the next pre-recorded program in train, he said a bit ruefully, 'I was just getting warmed up there.'

Over the course of several visits, he described to me his working practices. There are three key overlapping elements of which I want to highlight here. First is the broad set of aesthetic gestures he makes in organising his shows. These gestures that may or may not be entirely audible, but they place a definitive stamp on the sound and feel of his 
shows. Second is his engagement with the actual sounds and visceral feel of the music he presents. Again, his logic in connecting one tune to another might not be immediately obvious or audible, but it is a central force in shaping his shows. Third is the specificity of the aesthetic logic he employs to shape each program he presents.

This particular programmer was one of the most experienced and meticulously prepared presenters I had ever met. For nearly every $\mathrm{CD}$ he played on air, he created an explanatory guide to each track. He was in the practice of noting in his summary back announcements the specific line-up of the ensemble which performed the piece and the year it was produced. If relevant, he mentioned a song's highest chart position and a quick list of other hits by the same musicians for the sake of comparison. Inside each CD case he had with him in the studio, he had a carefully cut piece of paper on which he had painstakingly inscribed the vital details of every song.

But it wasn't just the obvious facts he noted. On several CDs he had written out what he called 'cheat sheets' for himself. By this I mean, he had mapped out the contours of several longer pieces of music by artists such as Holger Czugay, David Sylvian, Caravan, or Eric Dolphy. He did this because he felt the only way he could 'get away with playing this stuff' was by presenting longer form or more experimental works underneath the community announcements section of his show, during which he spent about fifteen minutes of reading out the details of upcoming events. He would time his reading to coincide with what he felt were the less interesting parts of a composition, allowing the more dramatic moments to intercede between the announcements. 'It's not ideal,' he explained to me, ' but it better than not playing them at all.'

These preparations extended into his home as well, determining the structure, content and placement of his entire music collection. Each time I saw him, he had brought a small, battered, cardboard box with him into the studio. It held about 25 CDs. Tracks on these CDs would form the basis for his show, although he often had a few special discs tucked away in his backpack. If he played a track on a particular CD, that one would be moved to one end of the box so he would know not to bring it again the following week. If he brought a CD out, but didn't play anything from it, he would try to put back in the box roughly where it had been before; he called these 'near misses.' When he got home, the CDs he played would be taken out of the starting line up and placed on the highest 
shelf of his CD rack, eventually making their way back down to the bottom shelves from which he usually chose titles to fill any open slots in the on air box. The "near misses' would remain in the on air box for another potential airing. He said that usually after a month or so, if he hadn't played anything off a near miss CD, it would go back in the rack at home, although they would not necessarily be relegated to the top shelf.

During our lengthy conversations, he explained that he had been presenting music on community radio for nearly thirty years and that each type of program he presented required a set of practices unique to that particular program. These practices are what work for this type of show and he seemed to think he had little choice but to use them. When I asked him about how he linked all these songs together, he did not seem particularly comfortable describing the aesthetic logics he was using. Instead, he relied primarily on visual or pictorial references, using adjectives such as 'dark' or 'light', referring to the sparseness and density of the sound, or the contrasts between each piece and the overall contour of all of them collectively, occasionally mentioning some tangential instrumental or textural connection. He was not using these terms in a musical way as such. He was using them as visceral terms, descriptive of the experience of sound, not the formal, structural or technical qualities of music. It is his overarching presenting philosophy, or more exactly, his aesthetic ideology that links and contextualises the music he plays specifically through this implied sense of material connection.

He said his main goal was to try to facilitate the imaginative experiences of his listeners. To do so, he used the specific practices I've described here as part of a larger practical regime of spontaneity and change. He tries to make sure that he doesn't rely on habits or templates by constantly subjecting himself to some fairly detailed, constantly evolving organisational exercises to keep things fresh. He summed it fairly simply when he said, 'how do people hear new things if all you ever play are things everybody already knows?'

The most obvious fact that struck me when watching this presenter work was that he, like most presenters, cannot actually listen to his own show very carefully, if he can listen to it at all. They are usually preparing the next several tracks, organising community announcements, preparing for interviews, writing out their back 
announcements or simply daydreaming. This presenter's show is in many ways tangentially perceived and its actual experience and consequences are largely imagined. It is important to acknowledge that the immediate visceral pleasure of playing music on radio is only one of many possible motivations for the presenters I've talked to and quite often is not even an immediate concern for some of them. Given the extensive preparations this particular presenter goes through each week, I think we can safely assume that his immediate and primary concern is the outwardly directed communicative gesture, not just the subjective pleasure of listening or presenting.

\section{Subjects of perception and aesthetic communication}

I am optimistically calling this presenter's practices 'civil' or possibly even 'democratic' because he is expressing larger values through other people's music. He does so through a series of communicative acts that are personal and institutional simultaneously. His programs are communicative acts directed outwardly founded on an inner calculus that may not always be clearly expressed or even obvious, but is certainly always present. Further, this presenter's practices are defined by and directed towards egalitarian forms of public expression made through an institution defined by a mutuality of experience and circumstance (see Fairchild, 2005).

As such, understanding his musical practices can tell us two things of crucial importance to the kinds of social relationships I am going to describe below. First, he is by definition centrally involved in the production of open, public aesthetic relationships that have potentially unforeseeable consequences. Second, these relationships inherently contain the conditions for the momentary subjective autonomy of those engaged in them. If these institutions have the potential to reshape our relations of perception, then surely they can help refashion our perceptions themselves. The important question to ask here is what models of civil and democratic communication might be applicable to specifically aesthetic communication.

A community radio station would seem to be a fairly straightforward enactment of a classically Habermasian model of democratic process (Habermas, 1996). Equitable forms of inter-subjective communication rest at the centre of a reasonably open and democratic polity and the processes by which discourse works are reasonably formal thereby possessing real binding power within the institution (Fairchild 2006). The very 
potential for any civil or democratic society seems to be realised, founded on creating a social space in which people are freely allowed to reach consensus through a rational and critical discourse defined by the transparency of the conditions of communication (Habermas 1989). But this highly idealised model, as worthy as it is, would seem to implicitly exclude what I regard as non-rational or less than rational discourses. Habermasian rationalism, while crucial for theorising political discourses, is insufficient for understanding aesthetic communication if only because the kinds of talk which define many musical discourses can often be vague, imprecise and tend towards the esoteric, or even the magical and irrational.

However, we can build on Habermas by drawing on a definition of aesthetics that takes into account its unusual character as a communicative act. Specifically, we need to understand those practicing a civil social aesthetics as intent on establishing relationships between what Thomas Docherty calls 'sovereign subjects of perception' (Docherty 2006:1, 156). Here, social aesthetics acts as a connecting communicative thread between perceiver and producer within which is contained an inherent opportunity for subjective change. The social aesthetics practiced by the presenter described above is primarily directed towards the establishment and maintenance of various types of communicative relationships constituted specifically through moments of perceptual openness leading to what Docherty argues is an inherent condition within the aesthetic, 'unforeseeability'. These social relationships are only extant at the moment we experience the art object. It is in that moment when we can see most clearly the potential for freedom the aesthetic contains (Docherty 2006:x). Music in particular seems unusually seeded with such moments of potential, in which we can imagine the impossible or enact the unforeseen. Attali might call it the 'heraldic moment' (Attali 1985).

This fuzzy idea of 'sovereignty' requires some clarification, however, as it suggests both the romantic fantasy and modernist fallacy of the indomitable individual. Docherty's keyword, 'potential', suggests that it is the very mutability of the freedom inherent in the aesthetic that produces the highly idealised forms of subjective sovereignty he seeks. The practical expression of this idea lies in the mundane exercise and inhabitation of one's subjectivity in such a way as to necessarily imply a sense of ownership and subjective autonomy. However, this sense of autonomy cannot exist 
without a necessary and concomitant uncertainty and vagueness, or what Bakhin called 'opacity,' inherent to the communicative act. As Bakhtin has noted, the word is 'always half someone else's,' and it is through this concept of opacity through which we can acknowledge the ambiguity of public communication by centralising what he called the stubborn resistance of words to mean what we say they mean (Garvey 2000:370, 378; Hirschkop 1999).

The subject can only become autonomous, can only imagine themselves to be sovereign, by rending texts open and accepting their inherently varied meanings by explicitly understanding what Bakhtin called 'the dialogic strands against which every utterance brushes.' By situating oneself between the discourses which constantly circulate around us, we can then struggle for autonomy by acting as skilled manipulators of what Bakhtin called 'heteroglossia', or the multiple languages of everyday life, constantly subjecting these forms of public expressivity to constant audit and potential transformation (Garvey 2000:378; Clark and Holquist 1984; Hirschkop 1999).

Perceptual relations that I view as civil and democratic are distinct in that the material conditions under which they occur must be conducive to these specific kinds of discursive openness. These conditions must be formal to a significant extent if they are to be subject the kinds of consequential public accountability Bakhtin's 'auditing' implies. They must also be marked by the exercise of equitably distributed, transparently exercised power. Without these necessary preconditions, the relationships these communicative gestures imply, in which subject relations and truth conditions tend towards egalitarianism, cannot exist. Of course, their mere presence can offer no guarantees either.

Overcoming larger, more exacting discourses of the familiar and the conventional are, of course, widespread throughout many contemporary spheres of musical experience. Community radio stations are by no means the only or even necessarily the best examples of places in which these values exist. They do, however, draw out into the public realm what can often be the intensely private aesthetic relations music fosters; this creates a space in which the discourses of music can tend towards ends that those involved can not imagine, expect, assume or foresee. The many other forms of 
recombinant musical practice now buzzing through a proliferating range of semi-public internet-based media spheres, for example, many of which are dialogic and discursively open, rarely subject their participants to any formal accounting for their behaviour; indeed, within many such communities, such regulation is often profoundly offensive. This is hardly a criticism, but simply an acknowledgement of the abundantly obvious. But, as Elmer has observed, many such spheres of media practice can too easily become self-selecting, segregated taste communities marked by what he calls an 'intransigent familiarity' (Elmer 2004:47-50). The issue here is what larger understandings formal, civil and democratic institutions can foster and how the places which make these understandings possible actually work.

\section{Places of perception and openings to communicative potential}

The material conditions for the enactment of communicative relationships inevitably shape the form and content of those communications themselves. We can see this in the musical practices of the presenter I've described above. When we use a discourse theory of democracy to describe the communicative relationships he is seeking, we need to bind them what Habermas refers to as publicly-formed opinion in a way that is egalitarian and discursively open (Habermas 1989). But when we say opinion, we also mean subjectivity and when we say subjectivity, we also mean experience. When we analyse this presenter's subjective experience of music presenting we have to understand it in relation to the places which facilitate, shape or even initiate that experience.

As Maxwell has persuasively argued, the places in which we experience music are not empty containers on which we imprint experience or identity. They are instead the 'primordial' conditions of 'sense, meaning and being' (Maxwell 2008:81). The places in which the making of musical meaning is enacted by music presenters and their audiences inevitably shape their presumptions and expectations. These in turn exert a defining influence on the sounds that are eventually produced, the order and context in which they are heard and the strands of logic and meaning sought to connect them. When this presenter stands in front of his CD collection filling his well-travelled box, he is in part submitting to the imagined will of the very people he is trying to entice and inspire. His choices are part of a larger discourse, the rules of which are embedded in the regulations shaping his use of the radio station and which evolve through debates or 
conversations he has with other presenters and community members. His musical practices are deliberately set out in public for the validation and ratification of peers, compatriots and strangers alike. When he enters the studio and begins his various musical improvisations, he is submitting to a logic he likes to believe is bigger than he is, one that occasionally boxes him into a corner.

The relationships he is trying to construct with his audience are shot through with an immanent potential for perceptual subjective change. One of the defining aspects of his musical practices is how he tries to work around even his own habits, prejudices and preferences which he views as impediments to the kinds of aesthetically communicative relationships in which he wants he and his listeners to be enmeshed.

His is an aesthetic of uncertainty designed to avoid imposing a uniform set of values or specific and immutable aesthetic criteria for musical inclusion or exclusion. His careful arrangement of his materials in specific relationship to each other, in his home, in his on air box and eventually on the radio itself are gestures taken explicitly to enhance his audience's perceptions of music he hopes will be either unfamiliar to them, or defamiliarised through careful, discerning, yet improvisational juxtaposition.

This presenter is using his imagined musical community to shape his own behaviour not only to serve his own interests, but theirs as well, beyond any assumptions he thinks they may harbour, into the realm of the unforeseeable. The logics he uses, the meticulous notations he maintains, the knowledge he gathers and disperses are not simply for self-edification or some patronising display of trivial musical superiority. They are the actualization of his community, creating a web of connecting particularities structured by a specifically civil aesthetic discourse, but not hemmed in by it, tinged with the faith of magical thinking, but not rendered passive by the sublime or the musically absolute.

He aspires to express a contingent truth made through the momentary associations of his chosen aesthetic materials. Towards the end of our last interview he summed his practices up with characteristic concision: 'You know, I could just burn a disc of what I need every week, but it's only in that moment when you find your apotheosis, through that satisfying connection'. 
To paraphrase Bakhtin, if the word always has a history that carries more than the intent of its user, then a song most certainly carries far more than the meaning it holds for the presenter. This presenter populated his music with his own intentions and his own accents, appropriating it and adapting it to his own expressive ideals. He is a producer and a consumer of musical meanings simultaneously, trying to stand outside the boundaries of any one discourse while remaining consciously tangled up in many of them. Here the opacity of the meaning of the expressive act is not simply unavoidable, but recognised and exploited. This presenter's conscious awareness of the heteroglossia of musical practices that surround him grows from his ability to situate himself in relation to these existing strands of dialogic meaning within which he is working, defined by his desire to avoid reproducing dominant discourses on music, familiar models of radio presenting, and even his own habits and comforts.

Just as importantly, the material networks of communication in which this presenter is enmeshed have that immanent potential for change that are a primary precondition for civil or democratically tinged communicative practices. These networks help establish the space needed to produce both the subjective sovereignty of a civil aesthetic discourse but also the communicative opacity that prevents these expressive practices from solidifying and becoming rigid iterations of existing discursive power relations. These civil communicative gestures, then, don't merely 'provide' opportunities for communicative equity, they embody them. They can create circumstances through which anyone who decides to become involved in the conversation can claim a stake in the proceedings on their own terms.

\section{Bibliography}

Attali, J. (1985) Noise: the political economy of music, Minneapolis: University of Minnesota Press.

Clark, K., and Holquist, M. (1984) Mikhail Bakhtin, Cambridge, Mass.: Harvard University Press.

Docherty, T. (2006) Aesthetic Democracy, Stanford: Stanford University Press.

Elmer, G. (2004) Profiling machines: mapping the personal information economy, Cambridge, Ma.: The MIT Press.

Fairchild, C. (2006) 'The grinding gears of a neo-liberal state: community radio and cultural production', Southern Review, 39(2), pp. 61-76. 
(2005) 'The Currency of Collusion: The Circulation and Embrace of the Ethic of Authenticity in Mediated Musical Communities', Journal of Popular Music Studies. 17(3), pp. 301-323.

Garvey, T. G. (2000) 'The value of opacity: A Bakhtinian analysis of Habermas's discourse ethics', Philosophy and Rhetoric, 33(4), pp. 370-90.

Habermas, J. (1996) Between facts and norms: contributions to a discourse theory of law and democracy, Cambridge, Mass.: MIT Press.

(1989) The Structural Transformation of the Public Sphere: An Inquiry into a Category of Bourgeois Society, Cambridge, Ma.: MIT Press,.

Hirschkop, K. (1999) Mikhail Bakhtin: an aesthetic for democracy, New York: Oxford University Press.

Maxwell, I. (2008) 'There's no there there.' In Bloustein, G., Peters, M. \& Luckman, S. (eds.) Sonic synergies: music, technology, community identity, Aldershot, UK Ashgate, 79-89.

Storey, J. (ed.) (1998) Cultural theory and popular culture: a reader, London: Prentice Hall. 